\title{
Validation of a Single-Time-Point Measurement of Total Abdominal Counts to Simplify Small Bowel and Colon Transit Analyses
}

\author{
Alan H. Maurer ${ }^{1}$, Rahul Parupalli ${ }^{2}$, Perry Orthey ${ }^{2}$, and Henry P. Parkman ${ }^{2}$ \\ ${ }^{I}$ Department of Radiology, Section of Nuclear Medicine and Molecular Imaging, Lewis Katz School of Medicine at Temple University \\ Hospital, Philadelphia, Pennsylvania; and ${ }^{2}$ Department of Internal Medicine Gastroenterology Section, Lewis Katz School of \\ Medicine at Temple University Hospital, Philadelphia, Pennsylvania
}

The Society of Nuclear Medicine and Molecular Imaging and European Association of Nuclear Medicine procedure guide on gastrointestinal transit currently indicates that the mean of total abdominal counts of 7 time points $(0-360 \mathrm{~min})$ is used to define the total abdominal counts for bowel transit studies. The purpose of this study was to investigate the variability of total abdominal counts during the initial $6 \mathrm{~h}$ of bowel transit and to determine whether a simplified, single-time-point measurement can be used. Methods: Thirty consecutive bowel transit studies were retrospectively analyzed. Patients received an oral dose of $4.6 \mathrm{MBq}$ $(125 \mu \mathrm{Ci})$ of ${ }^{111} \mathrm{In}-\mathrm{DTPA}$ in $300 \mathrm{cc}$ of water together with a standard egg white solid-phase, gastric-emptying meal to measure small bowel and colon transit. ${ }^{111}$ In-DTPA geometric mean and decay-corrected total abdominal counts obtained at $0,30,60,120,180,240,300$, and 360 min after meal ingestion were analyzed. The coefficient of variation was used to determine the variability of the mean total abdominal counts. Slope of the regression line, Student $t$ test, and a Pearson productmoment correlation coefficient (PCC) were also calculated to determine the correlation of total abdominal counts at each time point compared with the mean of all time points. Results: The mean coefficient of variation of total abdominal counts of each patient was $3.3 \%$, with a range of $1.1 \%-6.3 \%$. The mean of the slope of the regression line of the total abdominal counts of the patients was $-0.001 \pm 0.003$. There was no significant difference between the measured slope of the regression line compared with a line with a slope of $0(P>0.05)$. When the counts at each time were compared with the mean counts, there was no significant difference $(P>0.05)$. The PCC of each of the counts showed a significant and strong correlation between each interval and the mean total abdominal counts $(P<$ 0.01). Conclusion: There is no significant variability in geometric mean ${ }^{111} \mathrm{In}$-DTPA total abdominal counts during the initial $6 \mathrm{~h}$ of bowel transit studies. This can permit a more simplified analysis using the total abdominal counts from only a single time point.

\footnotetext{
Received Aug. 30, 2016; revision accepted Oct. 28, 2016.

For correspondence or reprints contact: Alan H. Maurer, Department of Radiology, Section of Nuclear Medicine and Molecular Imaging, Lewis Katz School of Medicine at Temple University Hospital, Broad and Ontario St., Philadelphia, PA 19140.

E-mail: amaurer@temple.edu

Published online Nov. 10, 2016.

COPYRIGHT (C 2016 by the Society of Nuclear Medicine and Molecular Imaging, Inc.
}

Key Words: gastrointestinal transit scintigraphy; gastric emptying; small bowel transit; colon transit

J Nucl Med Technol 2016; 44:239-242

DOI: 10.2967/jnmt.116.183368

$\mathbf{G}$ astric-emptying scintigraphy continues to evolve with more standardization of imaging protocols (1). Currently, solidmeal, gastric-emptying scintigraphy is most commonly ordered to assess patient symptoms of upper gastrointestinal dyspepsia when gastroparesis is suspected as a cause of a patient's symptoms. Scintigraphic gastrointestinal transit studies have been expanded to involve the ingestion of a radiolabeled solid, liquid, or combined solid and liquid meal. The liquid phase is used to measure both liquid gastric empting and small bowel and colon transit. A recent practice guideline has been adopted by the Society of Nuclear Medicine and Molecular Imaging (SNMMI) together with the European Association of Nuclear Medicine (EANM), which expands gastric-emptying scintigraphy to include measurement of both small bowel and colon transit $(2,3)$.

Effective, January 1, 2016, 2 new current procedural terminology codes, 78265 and 78266 , became available to report gastric-emptying scintigraphy with small bowel and colon transit studies. Therefore, studies of the motility of the entire gastrointestinal tract (stomach, small bowel, and colon) in which the small bowel alone or small bowel and colon transit are continuations of the gastric-emptying scintigraphy study can now be performed.

The current SNMMI EANM Practice Guideline on gastrointestinal transit indicates that the mean of total abdominal counts from 7 individual time points from 0 up to $360 \mathrm{~min}$ should be used to define the total abdominal counts available to fill the terminal ileum and colon when quantifying small bowel and colon transit studies (3). This recommendation was based on early studies using older $\gamma$-cameras in which there was concern for potential nonuniform counting rates from the photomultiplier tubes and that there could be significant variability in the measurement of total abdominal counts due to variable bowel geometry and depth-related attenuation of counts over the multiple imaging time points. 
We have observed in many small bowel and colon transit studies, however, that there is little variation in the measurement of the total abdominal counts that is used to calculate the percentage of activity in the terminal small bowel at $6 \mathrm{~h}$ after meal ingestion and the geometric centers of colon activity at 24, 48, and $72 \mathrm{~h}$. The purpose of this study, therefore, was to investigate the variability of geometric mean total abdominal counts during the initial $6 \mathrm{~h}$ of small bowel transit imaging and to determine whether a singletime-point measurement could be used to simplify the analysis.

\section{MATERIALS AND METHODS}

This was a retrospective review of prior patient imaging studies and data. Our institutional review board approved this retrospective study, and the requirement to obtain informed consent was waived. Thirty consecutive patient studies from a 3-mo period that were performed to measure combined small bowel and colon transit as part of a dualisotope mixed solid and liquid meal were retrospectively analyzed. The study population included 35 women and 5 men. Patients were aged $20-69 \mathrm{y}$. The mean body surface area of the patients was $1.76 \mathrm{~m}^{2}(\mathrm{Du}$ Bois method), with a range of $1.37-2.33 \mathrm{~m}^{2}$ (Table 1).

All acquisition parameters followed the SNNMI and EANM Practice Guideline using a combined liquid water and egg white, solidphase meal to record gastric emptying as well as small bowel and colon transit (3). Patients received an oral dose of $4.6 \mathrm{MBq}(125 \mu \mathrm{Ci})$ of ${ }^{111} \mathrm{In}-\mathrm{DTPA}$ in $300 \mathrm{cc}$ of water combined with $37 \mathrm{MBq}(1.0 \mathrm{mCi})$ of ${ }^{99 m} \mathrm{Tc}$-sulfur colloid in 120-g cooked liquid egg white in a meal including 2 slices of white bread and $30 \mathrm{~g}$ of strawberry jam.

A large-field-of-view $\gamma$-camera, Millenium MPR (GE Healthcare), was used for imaging. All images were obtained in a $128 \times$ 128 pixel matrix using a medium-energy collimator. The photopeak setting for ${ }^{99 \mathrm{~m}} \mathrm{Tc}$ is $15 \%$ at $140 \mathrm{keV}$. Both the $172-$ and the $247-\mathrm{keV}$ peaks for ${ }^{111}$ In with $15 \%$ windows were used.

To obtain the ${ }^{111}$ In-DTPA total abdominal counts, large rectangular manual regions of interest were drawn to encompass the entire abdomen and to determine the ${ }^{111}$ In-DTPA geometric mean and decay-corrected counts at times $0,30,60,120,180,240,300$, and 360 min after meal ingestion (Figs. 1-3; Table 2). We obtained an additional set of images at $30 \mathrm{~min}$. Although this is not required by the SNNMI and EANM Practice Guideline on gastrointestinal transit, this is added at our institution to help in evaluation of gastric accommodation and potential rapid gastric emptying.

The coefficient of variation was used to determine the variability of the mean of the total abdominal counts for each patient. The slope of the regression line, Student $t$ test, and a Pearson productmoment correlation coefficient (PCC) were also calculated to determine the correlation of the time-activity curve at each time point compared with the mean of all time points.

\section{RESULTS}

The mean coefficient of variation of time-activity curve of each patient was $3.3 \%$, with a range of $1.1 \%-6.3 \%$. The mean of the slope of the regression line of the measured counts of the patients was $0.001 \pm 0.003$. There was no significant

TABLE 1

Patient Demographics

\begin{tabular}{|c|c|c|c|c|c|}
\hline Patient no. & Age (y) & Sex & Weight $(\mathrm{kg})$ & Height (cm) & Body surface area $\left(\mathrm{m}^{2}\right)$, Du Bois method \\
\hline 1 & 37 & $\mathrm{~F}$ & 129.5 & 167.6 & 2.33 \\
\hline 2 & 50 & M & 88.6 & 182.9 & 2.11 \\
\hline 3 & 51 & $\mathrm{~F}$ & 53.2 & 152.4 & 1.49 \\
\hline 4 & 68 & $\mathrm{~F}$ & 65.0 & 157.5 & 1.66 \\
\hline 5 & 57 & $\mathrm{~F}$ & 66.4 & 154.9 & 1.65 \\
\hline 6 & 24 & $\mathrm{~F}$ & 46.8 & 170.2 & 1.53 \\
\hline 7 & 67 & $\mathrm{~F}$ & 111.4 & 172.7 & 2.23 \\
\hline 8 & 33 & F & 66.4 & 165.1 & 1.73 \\
\hline 9 & 59 & $\mathrm{~F}$ & 97.7 & 167.6 & 1.75 \\
\hline 10 & 30 & F & 51.4 & 167.6 & 1.57 \\
\hline 11 & 35 & $\mathrm{~F}$ & 86.4 & 170.2 & 1.98 \\
\hline 12 & 52 & $\mathrm{M}$ & 65.9 & 167.6 & 1.74 \\
\hline 13 & 28 & $\mathrm{~F}$ & 57.7 & 154.9 & 1.56 \\
\hline 14 & 52 & $\mathrm{~F}$ & 66.4 & 162.6 & 1.71 \\
\hline 15 & 37 & $\mathrm{~F}$ & 65.9 & 162.6 & 1.71 \\
\hline 16 & 52 & $\mathrm{~F}$ & 58.2 & 165.1 & 1.64 \\
\hline 17 & 52 & $\mathrm{~F}$ & 58.2 & 162.6 & 1.62 \\
\hline 18 & 51 & $\mathrm{~F}$ & 62.7 & 165.1 & 1.69 \\
\hline 19 & 40 & $\mathrm{~F}$ & 111.4 & 157.5 & 2.08 \\
\hline 20 & 46 & F & 80.0 & 172.7 & 1.94 \\
\hline 21 & 45 & $\mathrm{~F}$ & 90.9 & 165.1 & 1.98 \\
\hline 22 & 35 & $\mathrm{~F}$ & 50.0 & 165.1 & 1.53 \\
\hline 23 & 68 & $\mathrm{~F}$ & 79.1 & 177.8 & 1.97 \\
\hline 24 & 28 & $\mathrm{~F}$ & 65.0 & 160.0 & 1.68 \\
\hline 25 & 51 & $\mathrm{M}$ & 54.1 & 182.9 & 1.71 \\
\hline 26 & 20 & $\mathrm{M}$ & 55.9 & 165.1 & 1.61 \\
\hline 27 & 68 & $\mathrm{~F}$ & 47.3 & 162.6 & 1.59 \\
\hline 28 & 40 & $\mathrm{~F}$ & 50.0 & 157.5 & 1.48 \\
\hline 29 & 69 & $M$ & 83.2 & 177.8 & 2.01 \\
\hline 30 & 40 & $\mathrm{~F}$ & 41.8 & 157.5 & 1.37 \\
\hline
\end{tabular}




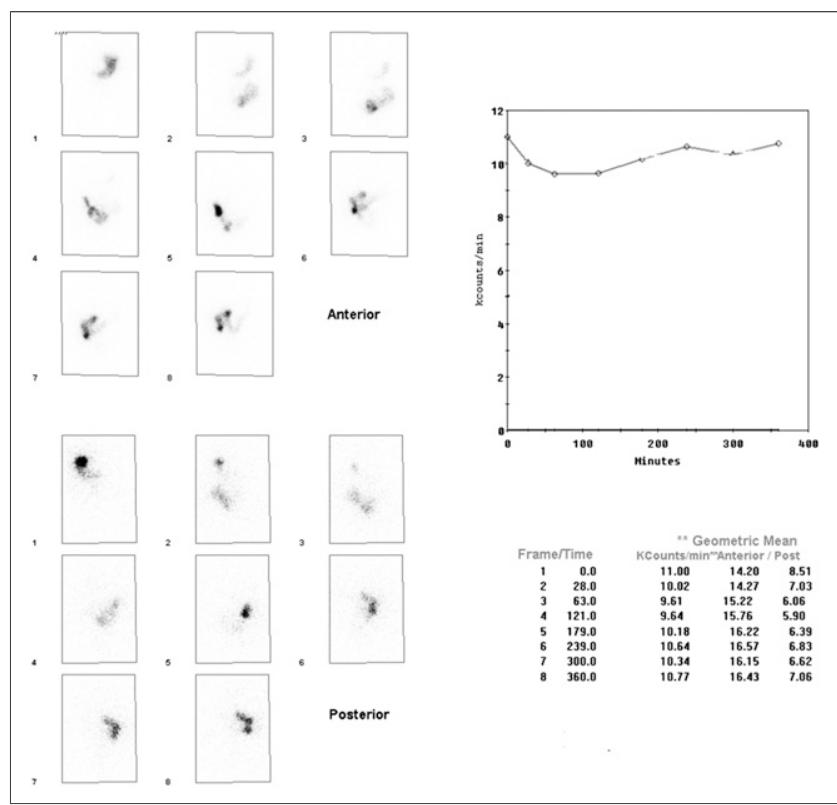

FIGURE 1. Anterior and posterior ${ }^{111}$ In-DTPA images of abdomen are shown with examples of large rectangular regions of interest used to obtain total abdominal counts for calculation of geometric mean and decay-corrected total abdominal counts for all time points. There is small time point-to-time point variation in total abdominal counts; however, variation from mean is always less than $10 \%$ (Table 2).

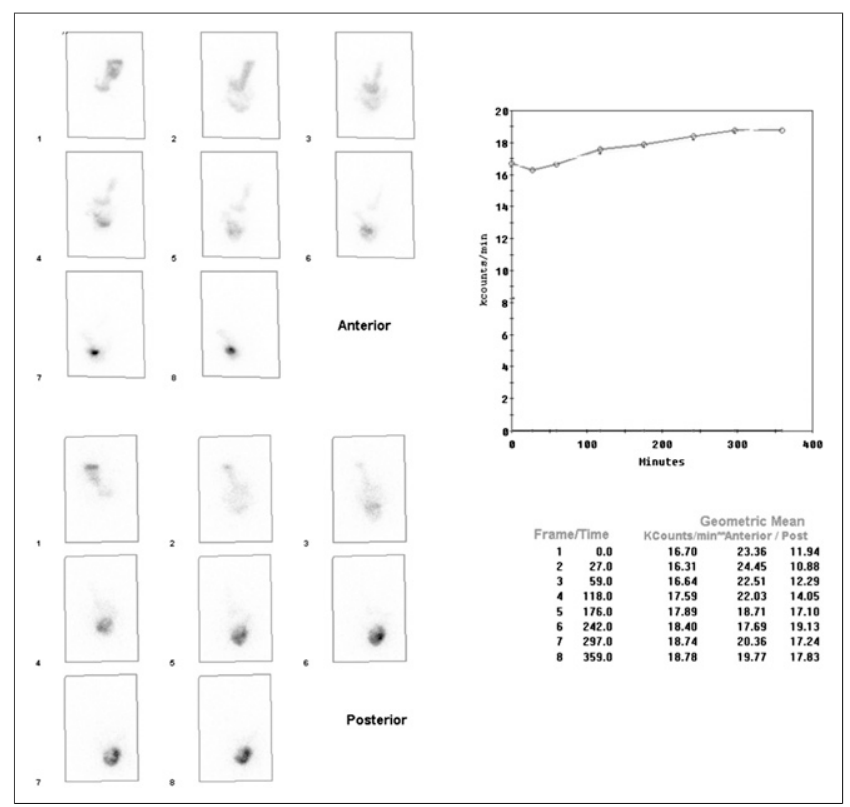

FIGURE 2. Orientation and regions shown are same as in Figure 1, however, this figure shows example of patient in whom there is mild increase in total abdominal counts over course of $6 \mathrm{~h}$ of imaging.

difference between the measured slope of the regression line compared with a line with a slope of $0(P>0.05)$. When the counts at each time were compared with the mean counts, there was no significant difference $(P>0.05)$. The PCC of each of the counts showed a significant and strong correlation between each interval and the mean counts $(P<0.01)$.

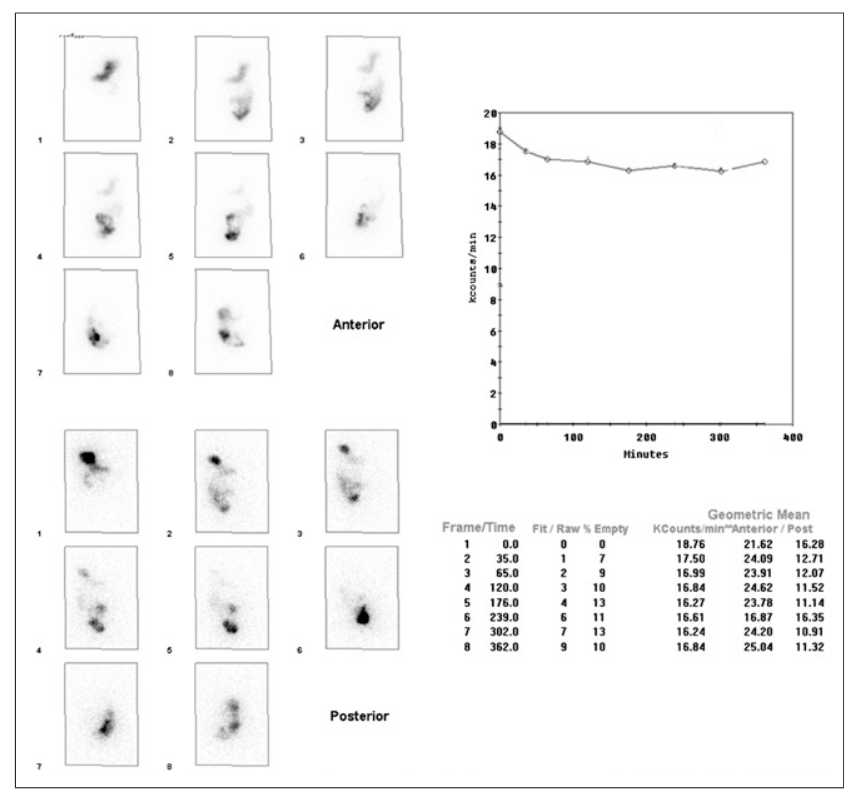

FIGURE 3. Orientation and regions shown are same as in Figure 1, but in this case there is mild decrease in total abdominal counts over course of $6 \mathrm{~h}$ of imaging.

\section{DISCUSSION}

Indications for gastric-emptying scintigraphy with smallbowel and colon transit imaging include, but are not limited to, evaluation of gastrointestinal tract transit abnormalities as a cause of symptoms in patients with known or suspected gastroparesis, dyspepsia, irritable bowel syndrome, chronic constipation, chronic diarrhea, chronic idiopathic intestinal pseudoobstruction, scleroderma, celiac disease, and malabsorption syndromes. In the evaluation of patients with constipation, gastrointestinal transit measurements may demonstrate a motility disorder or slow colon transit or may provide evidence to support a diagnosis of defecation disorder or functional rectosigmoid obstruction.

The American Neurogastroenterology and Gastrointestinal Motility Society and the European Society of Neurogastroenterology and Motility have stated in a position paper that wholegut transit scintigraphy (combined gastric emptying with small bowel and colon transit) is recommended for "detection of altered small-intestine transit in subjects with suspected diffuse gastrointestinal motility disorder" and that colon transit scintigraphy "offers reproducible and accurate performance, to measure regional colon transit in patients with suspected colonic motility disorders or more diffuse disorders involving the stomach or small intestine" (4). The recent approval of new current procedural terminology codes to perform both small bowel and colon transit studies will likely result in an increased volume of these studies being performed. The results of this study show that there can be considerable time savings in the processing of these studies using a single time point for total abdominal counts rather than measuring the mean total abdominal counts of the current recommended 7 time points. On the basis of the results of this study, use of a single-time-point measurement for 
TABLE 2

Summary of Measured Total Abdominal Counts (Kcounts/min) for All Patients and All Time Points

\begin{tabular}{|c|c|c|c|c|c|c|c|c|c|c|c|}
\hline \multirow[b]{2}{*}{ Patient no. } & \multicolumn{7}{|c|}{ Time point } & \multirow[b]{2}{*}{ Mean } & \multirow[b]{2}{*}{$\mathrm{SD}$} & \multirow{2}{*}{$\begin{array}{l}\text { Coefficient } \\
\text { of variation }\end{array}$} & \multirow{2}{*}{$\begin{array}{l}\text { Slope of } \\
\text { regression line }\end{array}$} \\
\hline & 0 & 60 & 120 & 180 & 240 & 300 & 360 & & & & \\
\hline 1 & 21.81 & 21.53 & 21.98 & 21.57 & 21.76 & 21.76 & 23.03 & 21.92 & 0.51 & $2.34 \%$ & 0.002 \\
\hline 2 & 24.67 & 22.93 & 21.20 & 20.90 & 21.37 & 23.28 & 23.49 & 22.55 & 1.41 & $6.27 \%$ & -0.002 \\
\hline 3 & 34.42 & 32.06 & 31.58 & 31.13 & 30.75 & 30.78 & 33.81 & 32.08 & 1.48 & $4.60 \%$ & -0.003 \\
\hline 4 & 17.77 & 16.85 & 16.65 & 16.84 & 16.34 & 16.66 & 16.28 & 16.77 & 0.49 & $2.94 \%$ & -0.003 \\
\hline 5 & 25.37 & 25.08 & 26.25 & 25.74 & 25.91 & 25.89 & 26.07 & 25.76 & 0.41 & $1.58 \%$ & 0.002 \\
\hline 6 & 25.02 & 24.59 & 23.89 & 24.46 & 24.19 & 25.36 & 24.94 & 24.64 & 0.51 & $2.06 \%$ & 0.001 \\
\hline 7 & 22.71 & 20.89 & 20.86 & 20.03 & 19.10 & 21.54 & 21.96 & 21.01 & 1.21 & $5.74 \%$ & -0.002 \\
\hline 8 & 22.55 & 22.13 & 22.32 & 22.34 & 22.88 & 23.85 & 23.07 & 22.73 & 0.59 & $2.61 \%$ & 0.003 \\
\hline 9 & 27.13 & 26.55 & 26.82 & 26.38 & 25.73 & 26.17 & 26.01 & 26.40 & 0.48 & $1.82 \%$ & -0.003 \\
\hline 10 & 17.06 & 16.30 & 16.49 & 16.09 & 15.19 & 15.16 & 15.24 & 15.93 & 0.75 & $4.70 \%$ & -0.005 \\
\hline 11 & 24.07 & 24.88 & 23.75 & 24.51 & 24.61 & 23.94 & 24.30 & 24.29 & 0.40 & $1.65 \%$ & 0.000 \\
\hline 12 & 19.65 & 20.07 & 19.42 & 19.63 & 19.59 & 19.14 & 19.56 & 19.58 & 0.28 & $1.43 \%$ & -0.001 \\
\hline 13 & 16.46 & 16.99 & 17.19 & 17.17 & 17.24 & 18.05 & 18.19 & 17.33 & 0.60 & $3.48 \%$ & 0.004 \\
\hline 14 & 23.20 & 22.31 & 21.88 & 22.76 & 22.34 & 23.34 & 22.41 & 22.61 & 0.52 & $2.31 \%$ & 0.000 \\
\hline 15 & 22.06 & 20.55 & 20.04 & 19.80 & 20.14 & 19.78 & 20.10 & 20.35 & 0.80 & $3.91 \%$ & -0.004 \\
\hline 16 & 21.90 & 22.31 & 22.36 & 22.70 & 23.11 & 22.24 & 23.38 & 22.57 & 0.52 & $2.31 \%$ & 0.003 \\
\hline 17 & 23.31 & 21.92 & 23.10 & 23.05 & 23.92 & 23.82 & 23.68 & 23.26 & 0.68 & $2.93 \%$ & 0.003 \\
\hline 18 & 18.89 & 18.83 & 18.37 & 18.57 & 19.40 & 20.02 & 19.16 & 19.03 & 0.55 & $2.91 \%$ & 0.003 \\
\hline 19 & 18.91 & 19.60 & 18.96 & 19.29 & 18.82 & 19.14 & 19.21 & 19.13 & 0.27 & $1.39 \%$ & 0.000 \\
\hline 20 & 16.15 & 15.82 & 14.76 & 14.32 & 13.92 & 13.90 & 14.43 & 14.76 & 0.89 & $6.06 \%$ & -0.006 \\
\hline 21 & 25.39 & 24.34 & 23.50 & 23.82 & 22.70 & 22.95 & 23.54 & 23.75 & 0.90 & $3.80 \%$ & -0.005 \\
\hline 22 & 23.81 & 22.57 & 21.69 & 21.69 & 20.89 & 21.00 & 21.01 & 21.81 & 1.06 & $4.86 \%$ & -0.007 \\
\hline 23 & 14.88 & 15.44 & 14.40 & 14.71 & 14.05 & 15.13 & 14.87 & 14.78 & 0.46 & $3.10 \%$ & -0.001 \\
\hline 24 & 17.76 & 18.66 & 18.72 & 18.97 & 18.94 & 18.82 & 19.59 & 18.78 & 0.54 & $2.90 \%$ & 0.004 \\
\hline 25 & 19.94 & 20.50 & 20.25 & 20.35 & 20.45 & 19.97 & 20.15 & 20.23 & 0.22 & $1.09 \%$ & 0.000 \\
\hline 26 & 20.80 & 18.74 & 18.23 & 18.04 & 18.13 & 17.85 & 17.74 & 18.50 & 1.06 & $5.74 \%$ & -0.007 \\
\hline 27 & 10.37 & 10.11 & 9.75 & 9.74 & 10.39 & 9.52 & 9.91 & 9.97 & 0.33 & $3.34 \%$ & -0.001 \\
\hline 28 & 14.08 & 13.17 & 12.99 & 12.36 & 12.94 & 13.67 & 13.35 & 13.22 & 0.55 & $4.18 \%$ & -0.001 \\
\hline 29 & 22.94 & 21.84 & 21.80 & 21.65 & 21.62 & 21.74 & 22.82 & 22.06 & 0.57 & $2.57 \%$ & 0.000 \\
\hline 30 & 22.38 & 21.10 & 20.55 & 20.89 & 21.31 & 20.53 & 19.75 & 20.93 & 0.81 & $3.89 \%$ & -0.005 \\
\hline Mean & 21.18 & 20.62 & 20.33 & 20.32 & 20.26 & 20.50 & 20.70 & 20.56 & 0.66 & $3.28 \%$ & -0.001 \\
\hline$P$ & 0.593 & 0.954 & 0.837 & 0.832 & 0.790 & 0.959 & 0.902 & & & & 0.095 \\
\hline PCC & 0.978 & 0.994 & 0.996 & 0.995 & 0.990 & 0.990 & 0.991 & & & & SD, 0.003 \\
\hline
\end{tabular}

total abdominal counts will result in only a small change in the values calculated for small bowel transit (percentage of activity in the terminal ileum) and geometric centers of colon transit (mean variation of $3.3 \%$, with a range of $1.1 \%-6.3 \%$ ).

There was consistency and lack of significant variability in measured total abdominal counts found in this study over the 8 time points measured in a diverse group of patients whose body surface areas ranged from small to large body habitus. This likely relates to the low administered oral ${ }^{111}$ In-DTPA activity, and therefore no significant dead-time losses or loss of counting efficiency, especially with modern photomultiplier tubes, resulted in low counting losses (5). The geometric mean correction using both anterior and posterior views has also been previously documented to provide good depth attenuation count correction $(6,7)$.

\section{CONCLUSION}

There is no significant variability in the measured geometric mean of ${ }^{111}$ In-DTPA total abdominal counts during imaging of the initial $6 \mathrm{~h}$ of small bowel and colon transit studies. This can permit a decrease in the time required for image analysis by potentially obtaining total abdominal counts only from a single time point. Because it is diagnostically necessary to still visually analyze the small bowel and colon transit patterns, imaging at all the recommended 7 time points, however, will still need to be performed.

\section{REFERENCES}

1. Donohoe KJ, Maurer A, Ziessman H, Urbain J, Royal H, Martin-Comin J. Procedure guideline for adult solid-meal gastric-emptying study 3.0. $\mathrm{J} \mathrm{Nucl} \mathrm{Med}$ Technol. 2009;37:196-200.

2. Mariani G, Paglianiti I. Joint SNMMI and EANM guideline for small-bowel and colon transit: an important step towards long-awaited standardization. Eur J Nucl Med Mol Imaging. 2014;41:405-407.

3. Maurer AH, Camilleri M, Donohoe K, et al. The SNMMI and EANM practice guideline for small-bowel and colon transit 1.0*. J Nucl Med. 2013;54:2004-2013.

4. Rao SS, Camilleri M, Hasler W, et al. Evaluation of gastrointerstinal transit in clinical practice: position paper of the American and European neurogastroenterology and motility societies. Neurogastroenterol Motil. 2011;23:8-23.

5. Williamson J. Statistical evaluation of dead time effects and pulse pileup in fast photon counting: introduction of the sequential model. Anal Chem. 1988;60:2198-2203.

6. Ziessman HA, Fahey F, Atkins F, Tall J. Standardization and quantification of radionuclide solid gastric-emptying studies. J Nucl Med. 2004;45:760-764.

7. Christian PE, Moore J, Sorenson J, Coleman R, Welch D. Effects of meal size and correction technique on gastric emptying time: studies with two tracers and opposed detectors. J Nucl Med. 1980;21:883-885. 